\title{
Los partidos políticos argentinos durante el siglo XX
}

Marcelo Cavarozzi

FLACSO-MÉXICO

UNIVERSIDAD DE GEORGETOWN, WASHINGTON

En este artículo se estudian dos etapas del sistema de partidos argentinos: la primera, en que se estructura un sistema que coadyuvó a la inestabilidad del régimen político, se extiende desde la ruptura electoral del orden oligárquico en 1916 hasta la recuperación de las formas democráticas después del gobierno militar en 1983. La segunda, comenzada en ese año, se inicia con lo que Cavarozzi llama punto de inflexión, contrastante de la anterior.

PIANTEAMIENTO DFL PROBL.EMA

$\mathrm{E}$ $s$ bien sabido que en Argentina; durante el medio siglo que siguió al golpe militar de 1930, la política no se organizó en torno al gobierno de los partidos. La institucionalidad política fue quebrada a menudo; esos quiebres, vinculados a los espasmos sucesivos de intervencionismo militar, condujeron a periódicos eclipses de los partidos, al menos en lo referente a su funcionamiento como instrumentos centrales del gobierno de la sociedad. Sin embargo, a pesar de que los partidos estuvieron habitualmente apartados de los procesos decisorios gubernamentales, la lógica de la acción partidaria no dejó de tener influencia sobre la política argentina, ni tampoco estuvo desvinculada de algunos de sus dilemas centrales.

En 1983 se inauguró una etapa de claros contrastes con la anterior. Por un lado, durante estos últimos doce años parece haberse normalizado la práctica de elecciones libres y competitivas y la amenaza de quiebres institucionales se ha reducido a un mínimo. La determinación de quién gobierna Argentina es el resultado de la confrontación entre ofertas partida- 
rias, y esta confrontación es resuelta, a su vez, a través de la periódica compulsa del voto de los ciudadanos. La estabilización de los procedimientos electorales ha contribuido, asimismo, a la rutinización de los procesos de circulación de partidos diferentes en las posiciones superiores de los poderes ejecutivo y legislativo, tanto a nivel nacional como provincial y local.

Por otro lado, si bien se han estabilizado las reglas electorales y los mecanismos de acceso y permanencia de los partidos en el gobierno, tanto las controversias inter e intrapartidarias, como las discusiones en torno al carácter del régimen político, parecen haber perdido relevancia. Esto se aplica especialmente a las cuestiones que afectan la vida cotidiana de la población, en particular aquellas vinculadas a los fenómenos económicos. Dicho de otro modo, los significados de la actividad partidaria, y asimismo de la acción política en general, se han ido distanciando de las motivaciones y orientaciones de importantes segmentos de la población.

La coyuntura de 1983 marcó un punto de inflexión en los procesos sociales y políticos argentinos. Este punto de inflexión implicó cambios en la política y simultáneamente un desplazamiento del posicionamiento de la política dentro de la sociedad global. Se transformaron los mecanismos políticos, es decir la forma de régimen, y también las funciones de la política en los espacios del mercado y la sociedad civil. En este último sentido se alteraron, por lo tanto, qué y cuánto se resuelve políticamente en dichos espacios.
Más concretamente, la fórmula política híbrida que había predominado desde la década de 1930 fue reemplazada por un régimen estable basado en las reglas y principios de la democracia política. Al mismo tiempo, se redefinieron sustantivamente las modalidades de "presencia" de la política en el mercado y la sociedad civil. En el marco de la matriz Estado-céntrica (en adelante MEC), que predominó durante las cuatro o cinco décadas posteriores a 1930, tanto la dilucidación de los conflictos distributivos como las disputas en relación con las potenciales áreas de igualdad de la sociedad civil (de las cuales las más importantes son la ciudadanía, el ámbito de trabajo, la educación, los entretenimientos de masas, los espacios urbanos) se desarrollaron preferentemente en las arenas estatales. Dentro de este patrón, que he definido como de "hiperpolitización estatista", el contenido y las dimensiones de los conflictos y las disputas aparecieron perfilados de modo relativamente claro, aunque las reglas para resolver unos y otras tendieran a ser discrecionales e inestables. ${ }^{1}$

El nuevo contexto político en el que actúan los partidos no está meramente definido por la estabilización de las instituciones democráticas. Es cierto que los partidos han visto desvanecerse la mayoría de los cuestionamientos de sus aspiraciones al gobierno de la sociedad; dichos cuestionamientos, como ya subrayé, estaban asociados al predominio de la fórmula híbrida del periodo anterior. Pero, al

1 "Politics", 199/. 
mismo tiempo, los cambios en curso han afectado, y redefinido, el sentido mismo de la acción política: dentro de la matriz Estado-céntrica se trataba básicamente de erosionar al gobierno para promover las reivindicaciones de clases y sectores sociales; en la etapa actual, se trata de gobernar.

En este artículo examino, en principio, cómo se conformó en Argentina el sistema contemporáneo de partidos. Para ello parto de la idea de que dicho proceso fue de ${ }^{\text {carácter }}$ interactivo. La arquitectura del sistema partidario fue uno de los factores que contribuyó a la inestabilidad del régimen político pero, a su turno, la dinámica perversa del sistema partidario fue alimentada por otros rasgos peculiares del régimen. En la segunda parte del artículo me concentro en la nueva etapa, abierta a partir de la transición democrática de comienzos de la década de 1980. En esta etapa, la mayoría de los dilemas heredados de las décadas previas se resolvieron ( $y$ otros se disolvieron); al mismo tiempo, sin embargo, emergieron problemas novedosos que redefinen los desafíos enfrentados por los partidos políticos en Argentina.

UN SISTEMA IDE PARTIDOS "CONTRANATURA": CONSTRUCCIÓN DE IDENTIDADES, DISTRUCCIÓN DE INSTTTUCIONES (1916-1983)

En Argentina el proceso de reunificación territorial y de construcción del Estado nacional se desplegó entre la década de 1860 y los años de la prime- ra guerra mundial. Este proceso estuvo asociado a la estructuración de un sistema político restrictivo y oligárquico; en dicho sistema un conjunto de elites de origen provincial se agruparon de manera bastante flexible en el Partido Autonomista Nacional (PAN), que fue el mecanismo que les permitió controlar monopólicamente tanto las "situaciones" provinciales como el ejecutivo nacional.

En 1912, la sanción de la ley Sáenz Peña condujo al ocaso del sistema oligárquico al frustrarse el proyecto de liberalización controlada que aspiraba a integrar a la Unión Cívica Radical (UCR) como la oposición legal al PAN. La UCR había actuado desde 1890 como una oposición contestataria del orden oligárquico, habiendo recurrido incluso a la vía de las rebeliones militares: La estrategia de reforma controlada de los conservadores fue desarticulada por el desagradecido partido opositor. Favorecidos por la fragmentación de las fuerzas del régimen oligárquico, los radicales triunfaron, en forma relativamente inesperada, en las elecciones de 1916. Esas elecciones permitieron el acceso de su líder, Hipólito Yrigoyen, a la presidencia.

El agotamiento del sistema oligárquico no se tradujo, sin embargo, en la consolidación de un régimen alternativo basado en la vigencia estable de los principios y reglas de la democracia liberal. Una década y media después de su primera victoria electoral, y cuando Yrigoyen había alcanzado nuevamente la presidencia, los radicales fueron desplazados violentamente del poder; se interrumpió así üna larga 
etapa de casi siete décadas de continuidad institucional. El golpe militar de 1930 , entonces, inauguró un periodo de más de medio siglo de inestabilidad institucional. En cierto sentido, el derrumbe del orden constitucional puso fin a la hegemonía conservadora, pues deshizo el esquema de apertura gradual de las instituciones liberales ideado por los fundadores de la República Argentina entre 1862 y 1890. Pero además, y paradójicamente, la crisis institucional desencadenada en 1930 también arrastró a los cuestionadores reformistas del orden oligárquico, quienes fueron las víctimas del golpe militar de 1930. Este golpe no fue simplemente un intento de restauración conservadora, sino además el hito que marcó el aborto de la democracia política en Argentina. A partir de ese momento los partidos que habian planteado las demandas de democratización, como los radicales, los socialistas y los demócratas progresistas, vieron reiteradamente frustradas sus aspiraciones de construir un sistema pluralista de gobierno. Sin embargo, esa circunstancia no impidió que durante la década de 1940 , de todos modos, se conformara un espacio político ocupado por fuerzas partidarias. Este espacio, sin embargo, no podría ser caracterizado como un sistema de partidos en un sentido estricto, ya que las principales fuerzas que lo ocuparon, el radicalismo y el peronismo, no llegaron a aceptarse plenámente como interlocutores políticos válidos. El redefinido espacio partidario fue completado por dos polos de carácter virtual: la izquierda y la derecha. Éstos tuvieron alguna capacidad para constituirse en referentes programáticos, a pesar de que las respectívas organizaciones partidarias prácticamente desaparecieron del mapa electoral. A excepción de episodios fugaces, y que inmediatamente demostrarían su reversibilidad, los partidos de derecha y de izquierda no superaron niveles mínimos de votación ni alcanzaron dimensiones nacionales.

Comprensiblemente, la constatación de que la fórmula política argentina se caracterizó por la permanente inestabilidad institucional ha llevado a muchos analistas a explorar las causas de dicho fenómeno. Resulta bastante obvio que la inestabilidad política contribuyó de manera decisiva a apartar a Argentina de la ruta de "nuevo país" exitoso en la que parecía bien encaminado a principios del siglo $\mathrm{XX}$. La mayoría de los analistas ha tendido a privilegiar una causa como la variable explicativa determinante. Sin embargo, no ha habido coincidencia en torno a cuál fue dicha causa; por el contrario, se identificaron factores alternativos asociados, a su vez, con diferentes momentos de la política del presente siglo.

En este trabajo quiero explorar un camino alternativo. Para ello voy a distinguir tres variedades de interpretaciones del fenómeno de la inestabilidad política en Argentina; estas interpretaciones, como apunté en el párrafo anterior, han resaltado procesos vinculados a diferentes etapas del siglo XX. Este ejercicio clasificatorio me permitirá sugerir algunos criterios que podrían servir para proponer una interpretación más integrada. 


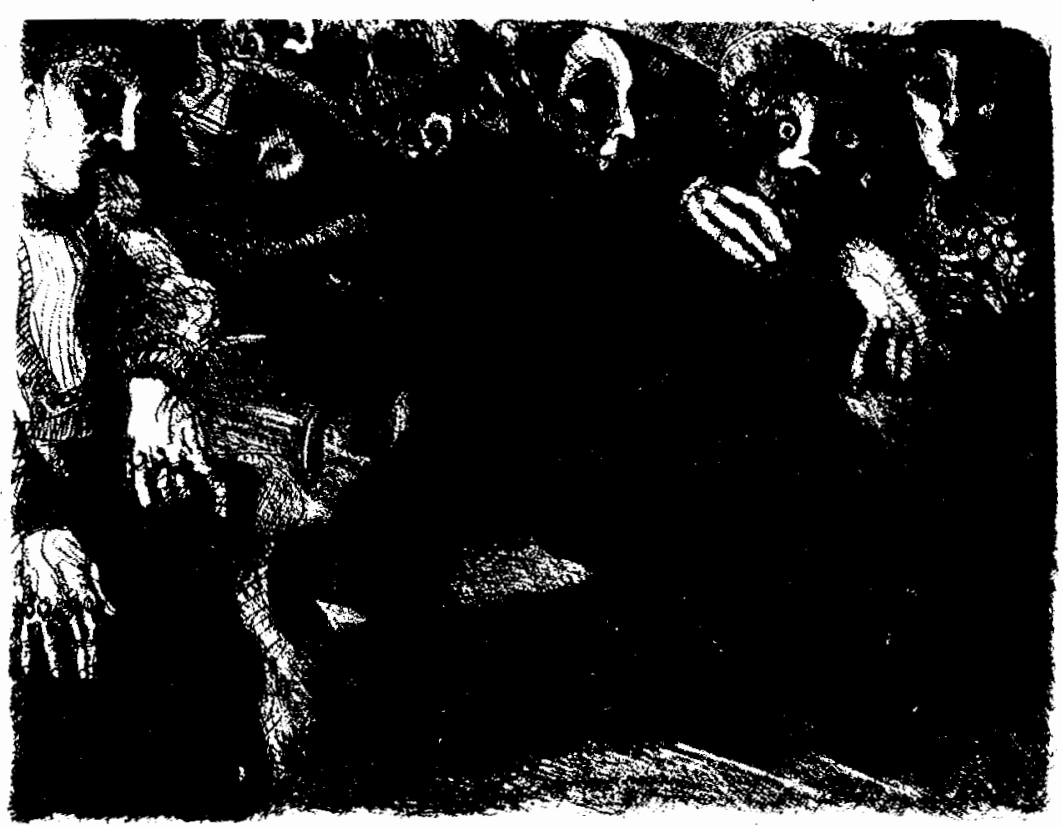

En primer lugar, una corriente de autores sostuvo que la pérdida de fuerza electoral del partido conservador, producida en el momento de implantación del sufragio universal masculino, y su posterior desaparición como fuerza nacional, estuvo vinculada al apoyo recurrente que las clases capitalistas prestaron a las salidas autoritarias. Privados de un partido afin a sus posturas que tuviera la capacidad real de ganar las elecciones, se adujo, los capitalistas argentinos favorecieron la instalación de regímenes militares o civiles fraudulentos que restringieran el peso de las mayorías en la elección de los gobiernos.

Una segunda corriente de autores privilegió la divisoria de aguas de tres décadas más tarde; es decir, aquella asociada con la emergencia del peronismo. El poner énfasis sobre el impacto de la irrupción del peronismo se asoció con la metáfora que describía Argentina como "sociedad fuerte, Estado débil". Esta metáfora aludió a un estilo de acción política inducido, al menos en el plano discursivo, por el peronismo de la primera época: en el marco de dicho estilo, las organizaciones sectoriales de clase - sindicatos $\mathrm{y}$ asociaciones empresariales- o simplemente las corporaciones-que además de los primeros incluyeron también a las fuerzas armadas y la Iglesia católica- actuaron directamente en la política. El corolario de estilo de acción política, concluyeron estos autores, fue el debilitamiento 
del régimen político, o más precisamente, el arrasamiento de las arenas institucionales tipicamente asociadas con la vigencia de los partidos políti$\cos ^{2}$

Finalmente, otra corriente de interpretación resaltó el efecto desestabilizante y por lo tanto destructor de las instituciones (incluidos los partidos políticos) de las intervenciones militares que se sucedieron a partir de la década de 1950 . El primero de la serie de golpes contemporáneos, el de 1955, tuvo como propósito central la eliminación del peronismo al proponerse incluso el restablecimiento de la democracia de partidos. Para ello esgrimió el argumento de que la "dictadura", encabezada por el líder populista, había conspirado en contra del desarrollo democrático. Sin embargo, a partir de la intervención militar de 1962 , las fuerzas armadas fueron redefiniendo su objetivo; de la visión de una democracia tutelada pasaron gradualmente a la articulación de un proyecto de dictadura sine die que aspiraba a desplazar al conjunto de las fuerzas partidarias. El proyecto de los militares, por un lado, apuntaba a ocluir permanentemente los canales electorales y, por el otro, procuraba redefinir la gestión gubernamental como una cuestión técnico-administrativa, y no política.

Los militares fracasaron tanto en sus proyectos minimalistas como ma-

2 lin cicrta forma Berins y Collicr, Shaping, 1991, postulan que la modalidad de incorporación política de la clase obrera argentina, producida a través del peronismo, tuvo como kegado la conformación de un jucgo político "imposibic". ximalistas. Varios autores han señalado que, a pesar de ello, los interregnos militares tuvieron como efecto la generación de hiatos que impidieron la consolidación de un sistema político basado en el gobierno de los partidos. ${ }^{3}$

Decía que en esta sección me propongo sugerir algunos criterios para elaborar una interpretación más integrada del periodo posoligárquico. Parto para ello de la sugerente imagen propuesta por Liliana De Riz, aquella que define al sistema político argentino como algo que no llegó a ser, es decir, como algo que no cuajó "ni en una democracia estable, ni en una dictadura sólida". Dicha imagen, empero, vale sólo como una primera aproximación; resulta necesario ir más allá de ella. Esto es así porque incluso una fórmula política que no se estabiliza, es decir que no cuaja en regímenes institucionales perdurables, no deja por lo general de responder a ciertas pautas. En el caso argentino, en particular, la preeminencia de los cortes institucionales (fenómenos que, por definición, son de carácter destructivo) no impidió que, en torno de ellos, se fueran entretejiendo pautas de comportamiento político: por ello vale la pena caracterizarlas con mayor precisión.

El periodo de democratización del régimen oligárquico argentino, y su desenlace abortado, se extendió durante tres décadas: desde la sanción de la ley Sáenz Peña en 1912 hasta el golpe militar de 1943 que puso fin a

${ }^{3}$ Intre cllos De Ri\%, Retomo, 1981 y Cavatrozri, Autorilarismo, 1983. 
la restauración conservadora. Durante esas décadas la sociedad argentina procesó, en primer lugar, los efectos de la modernización social y económica producida a partir de 1880; el proceso de expansión económica con índices de crecimiento extremadamente altos, junto a la masiva inmigración extranjera, la construcción estatal de un espacio nacional y la universalización de la educación pública primaria, habían, en la práctica, creado una sociedad nueva. ${ }^{4}$ En segundo lugar, a partir de 1930, la industrialización y las migraciones internas (éstas fluyeron principalmente de las provincias pobres a las ciudades del litoral) transformaron de nuevo al país, en especial a los modos de vida cotidianos de una gran parte de su población urbana.

En esa sociedad, cuya dato más significativo a lo largo de seis o siete décadas había sido su permanente flujo, la ruptura política de 1930 actuó como un factor corrosivo de instituciones que todavía no habían arraigado plenamente, desde las fuerzas armadas hasta el parlamento y los partidos políticos. En particular, la precaria estructura partidaria que había emergido en el momento de implantación del sufragio universal masculino no llegó a armarse como sistema.

\footnotetext{
${ }^{4}$ El lenómeno de creación de una sociedad nueva no tuvo casi ningún precedente en América Latina o cn otras regiones del mundo. Gracias al aporte inmigratorio, la población total se multiplicó por cuatro entre 1869 y 1914 . lentre 1900 y 1929, a sti vez, cl producto bruto creció a un pronedio anual del $4.8 \%$, micntras que sc construyó una de las redes de ferrocarriles más extensas a nivel mundial. También la aldea de mediados del siglo XIX, Buenos Aires, se transformó en una de las grandes ciuclades del mundo.
}

LOS PARTIDOS POLITICOS ARGENTINOS
Las camarillas de notables que se habían organizado en torno al PAN no lograron generar un partido conservador de masas. A su vez, los radicales, transformados en el único partido nacional como resultado de la debacle conservadora y de la paralela incapacidad socialista para trascender los grandes centros metropolitanos, oscilaron entre dos extremos igualmente negativos desde la perspectiva de la consolidación de un sistema partidario democrático. Por un lado, no siempre rehuyeron la tentación de convertirse en un movimiento dominante $y$, hasta cierto punto, excluyente de las oposiciones; $;$ por el otro, las proscripciones a las que fueron sometidos por los regímenes fraudulentos del periodo 1930-1943 los alejaron de la posibilidad de llegar al gobierno $y$, por ende, explicablemente reforzaron su reticencia a integrarse dentro de un esquema de intercambio político.

Durante el periodo de la denominada Década Infame se recurrió a la proscripción del partido mayoritario y al falseamiento de los resultados de los comicios. La falta de respeto a las reglas de la democracia electoral, en vez de generar demandas por su restauración produjo una sistemática dc: valuación de los valores y actitudes democráticas. El régimen político que funcionó entre 1930 y 1943 no fuc más que una ostensible simulación de la democracia. Empero, la dinámica que

5 El slogan radical que oponía "la causa" a "el réginen", anticipaba que el particlo de Y'rigoyen no estaría del todo dispuesto, una ve\% en cl poder, a otorgar a sus adversarios la legitimidad que les había negado descle la oposición. 


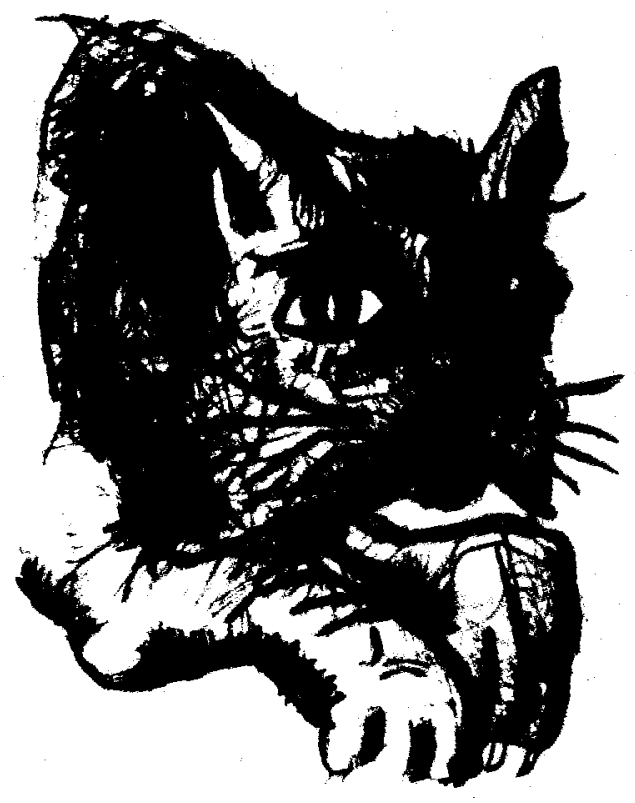

se desplegó durante esos años distorsionó las imágenes políticas: en vez de que la restauración conservadora fuera simplemente percibida como una farsa de la democracia, la democracia en sí misma terminó siendo concebida como una farsa. La ilegitimidad de los dirigentes conservadores se tornó patente, pero ella también impregnó a los políticos radicales, quienes oscilaron entre la condena al fraude, desde afuera, y la incorporación a las viciadas instituciones parlamentarias para negociar, desde adentro.

Uno de los legados de la frustrada democratización fue el predominio del escepticismo, e incluso del cinismo político, en importantes franjas de la población argentina. Perdido el sentido de la participación electoral para la mayoría, la política in toto, los partidos incluidos, pasó a ser vista como algo negativo, como el coto de dirigentes corruptos y dedicados exclusivamente a las componendas de cúpula; el contubernio como se lo llamó en esos años. En este contexto germinaron la apatía y la retracción políticas $y$, en última instancia, prevalecieron visiones y actitudes antipolíticas.

El epílogo de la restauración conservadora estuvo marcado por una conjunción de eventos bastante accidentales. En el curso de pocos meses, entre 1940 y 1941 , murieron por causas naturales los tres personajes que se habían convertido en los ejes de una posible liberalización del régimen no democrático: el presidente Roberto Ortiz, un ex radical antiyrigoyenis- 
ta; el general Agustín Justo, quien se había consolidado como el hombre fuerte del ejército poco después de 1930 y había ejercido la presidencia entre 1932 y 1938 , y el presidente de la UCR, Marcelo Torcuato de Alvear. La desaparición de Ortiz, Justo y Alvear abrió un espacio a los dirigentes más tradicionales, quienes representados por el reemplazante de Ortiz en la presidencia, Ramón Castillo, quisieron dar marcha atrás en el proceso de liberalización. Al bloquear una posible transición democrática, los políticos conservadores terminaron de antagonizar al grueso de la clase política. Todavía más decisivo resultó el hecho de que la mayoría de la clase política perdió contacto con una nueva realidad que se estaba conformando al compás de dos transformaciones de fundamental importancia. Por un lado, se produjo una redefinición de los desacuerdos internos del ejército, marcados fuertemente por la aparición de una fuerte minoría nacionalista y pronazi; estos grupos comenzaron a cuestionar la estructura institucional del Estado argentino. Este cuestionamiento se alimentó en el disgusto con los "políticos tradicionales" -es decir, los conservadores que habían retornado a las posiciones de poder durante la década de 1930 y sus adversarios radicales- y en la urgencia por construir una maquinaria capaz de mantener a Argentina como la principal potencia de la región.

Por el otro lado, la articulación de una propuesta "nacional-autoritaria" de carácter militarista coincidió con la emergencia, inicialmente poco visible, de una novedosa ola de demandas sociales. Estas nuevas demandas, más que postular la ampliación de los espacios de participación política institucional, como había sucedido a principios de siglo, reclamaron la expansión de las "áreas de igualdad social", para utilizar el concepto de Pizzorno. En general, se ha resaltado la dimensión redistributiva de este fenómeno; debe subrayarse, empero, que las nuevas demandas también abarcaron aspectos sociales y culturales. Ellas implicaron un conjunto de cuestionamientos, múltiples y heterogéneos, a los patrones de jerarquía social: los plebeyos, desde los trabajadores y los "cabecitas negras", hasta los hijos de los inmigrantes ya integrados a la clase media, cuestionaron el predominio de la oligarquía patricia. ${ }^{6}$ El exacerbado predominio oligárquico, que se apoyaba en el fraude político descarado, aparecía relativamente desprovisto de las pretensiones ilustradas y progresistas que habían constituido un atributo creíble del discurso de la elite conservadora hasta los años de la primera guerra mundial. ${ }^{7}$

El eje de los cuestionamientos se desplazó: giró de lo político-institucional a lo económico-social e ideoló-

6 El término de "cabecita negra" fue despectivamente aplicado a los inmigrantes del interior de origen mestizo. Debe quedar claro, empero, que los "cabecitas" eran igualmente despreciados tanto por los integrantes de las clases altas como por los descendientes de los inmigrantes del periodo 1870-1914.

7 Uno de los documentos socialcs más formidables de la época fue el tango Cambalache en el que su autor, Enrique Santos Discépolo, aludía a la crisis cultural de Argentina en los años treinta al ridiculizar a los ocupantes de las posiciones superiores de la escala social. 
gico; la reivindicación ciudadana, por ende, fue reemplazada por las demandas del pueblo.

Asimismo, el giro que se produjo a partir de la década del cuarenta se montó sobre un fenómeno que los gobiernos conservadores posteriores a 1932 habían promovido, aunque sin llegar a percibirlo en toda su complejidad: la emergencia de un Estado interventor que no sólo actuó como agente explícito de los cambios económicos y sociales, sino que además se transformó en el mecanismo principal a través del cual los distintos grupos sociales pasaron a procesar sus intercambios políticos. La mayoría de los políticos de la coyuntura no se dio cuenta del carácter de los cambios en curso: casi todos los dirigentes de los partidos tradicionales estaban enfrascados en los forcejeos en torno a una transición a la democracia que nunca llegaría. Sólo algunos disidentes, de origen radical, conservador y de izquierda, percibieron que las transformaciones del contenido y la forma de las relaciones que se estaban produciendo entre el Estado y los individuos tenían un profundo impacto sobre las maneras de percibir la política. Pero otro personaje, que llegaría mucho más lejos que los disidentes partidarios de la década de los treinta, también mostró poseer un aguzado olfato político. Éste no fue otro, claro está, que el militar que dominaría la política argentina durante las tres décadas posteriores, Juan Domingo Perón.

El coronel Perón, forzado a redefinir un juego político en cuyas pistas tradicionales estaba condenado a la derrota, tuvo la habilidad de interpre- tar, y a la vez contribuir a generar, los rasgos de la "nueva Argentina". ${ }^{8}$ Aque-llas pistas eran, por un lado, los cuarteles del Ejército $\mathrm{y}$, por el otro, los comités partidarios. En los primeros, Perón y sus aliados fueron inicialmente derrotados: la interna militar no los favoreció y Perón resultó brevemente destituido de sus cargos, que incluían la vicepresidencia de la nación y la secretaría de Trabajo y Previsión, a principios de octubre de 1945. En los comités también fue rechazado; aunque Perón tuvo éxito en atraer a numerosos dirigentes conservadores y sindicalistas socialistas, fracasó en sus intentos de lograr acuerdos con las principales dirigencias partidarias en apoyo de la candidatura presidencial que lanzó en aquel año. Como resultado de ello, todos los partidos políticos significativos se agruparon, formal o informalmente, en la.llamada Unión Democrática, que fue claramente derrotada por Perón en las elecciones presidenciales de febrero de 1946.

La principal razón del triunfo peronista fue la invención de una nueva pista política; es decir de un canal alternativo de comunicación y representación política: la plaza pública, o más propiamente la plaza del pueblo. A partir del 17 de octubre de 1945, organizados por Eva Perón y sus amigos sindicales, los trabajadores y sectores de la plebe urbana del Gran Buenos Aires invadieron las calles de la ca-

8 lil peronismo, o justicialismo como scria también denominado el partido de Perón, sc refirió a sus programas como los catalizadores dc una nucva Argentina. 
pital y ocuparon la principal plaza de la ciudad y donde estaba el edificio sede del presidente, la Plaza de Mayo. Ésta se transformó, tanto a nivel simbólico como concreto, en el lugar de encuentro privilegiado entre el líder y las masas.

Operando "al costado de" la pláza, y en una relación en parte complementaria, estaban también la CGT (Confederación General del Trabajo) y los sindicatos. Hasta que Perón fuera derrocado en 1955, los sindicatos funcionaron preferentemente como correas de transmisión de las políticas y orientaciones del gobierno peronista, más que como representantes de los trabajadores. ${ }^{?}$

El pueblo en la plaza, fusionado con el líder, implicaba la ficción de una comunicación instantánea y directa; el principal efecto de la fórmula peronista fue la desvalorización de los mecanismos de las relaciones de representación parlamentaria, necesariamente indirectos. Aunque estos mecanismos no fueron plenamente clausurados, quedaron relativamente al margen de la política. Este elemento contribuyó a ahondar la escisión que se planteó de entrada entre el peronismo, por un lado, y los partidos políticos, por el otro. Como los partidos de izquierda y derecha prácticamente desaparecieron, se conformó un siste-

9 A menudos se ha exagerado el componentc corporativo del sistema de gobicrno de la primera década peronista. I.as corporaciones empresariales precxistentes que se opusieron al gobierno fucron intervenidas, $y$ la Confederación General I:conómica progubcrnamental fuce creada pocos meses antes del derrocaniento de Pcrón en 1955. ma político dual y escindido: los peronistas en el gobierno y un polo opositor, ocupado casi exclusivamente por los radicales, que fue "arrinconado" por las prácticas semiexcluyentes de sus adversarios $y$, a su vez, fue convirtiéndose en un participante desleal del juego institucional.

A semejanza de lo que había sucedido durante el periodo 1930-1943, nuevamente la ITCR quedó en cierto sentido afuera de la política, no ya como resultado del fraude electoral, sino como efecto del parcial vaciamiento político de los canales partidarios. El arrinconamiento de la oposición partidaria benefició en el corto plazo al gobierno peronista: el apoyo electoral recibido por los radicales fue reduciéndose a la vez que su capacidad para influir sobre las políticas públicas fue prácticamente nula. Sin embargo, en el más largo plazo la falta de espacio para las oposiciones conspiró contra el peronismo, que fue depuesto del poder en 1955, y finalmente también desarmó la posibilidad de consolidar un sistema político pluralista.

Desde el punto de vista de funcionamiento institucional de la política, el principal legado de la década peronista fue, por ende, negativo. Los canales de participación política quedaron escindidos de los mecanismos formales de representación institucional y de la arena de los partidos políticos. En el caso de los sectores populares, especialmente, los procesos a través de los cuales accedieron a las "áreas de igualdad" y fueron incluidos en el abanico de servicios del Estado, se desarrollaron totalmente al 
margen de los partidos y del ámbito parlamentario. Esta experiencia se constituiría en un legado con fuerte impacto en la memoria colectiva de los argentinos; en dicha memoria se reforzarían las imágenes negativas con respecto a la política canalizada a través de las instituciones.

En la siguiente etapa, como ya adelanté en las páginas introductorias, se agudizó la inestabilidad política. Los sucesivos regímenes militares inaugurados en 1955, 1962, 1966 y 1976 fracasaron en la estabilización de toda fórmula política que se propusieron implantar, fuera ésta autoritaria o semidemocrática. Por su parte, los gobiernos civiles instalados en 1958, 1963 y 1973 , además de ser jaqueados desde su misma incepción por las fuerzas armadas, tampoco lograron articular una fórmula política basada en la competencia partidaria. Los dos primeros, conducidos sucesivamente por las dos fracciones en las que se dividió la UCR tras la caída del peronismo, nunca pudieron trascender los parámetros del juego imposible en el que quedaron encajados; es decir, la proscripción del peronismo y la inevitable tentación de triunfar en las elecciones atrayendo el apoyo de los votantes peronistas. ${ }^{10}$

El último de esos tres gobiernos superó los problemas de sus antecesores, pues las elecciones sin proscripciones resultaron en el retorno al poder del peronismo y del mismo general Perón en 1973. Sin embargo, el

${ }^{10}$ O'Donnell analizó los rasgos del que bautizó como "juego imposible" en su Moder. nization, 1973. estallido de los conflictos internos del peronismo que terminaría por derrumbar al gobierno de Isabel Perón tres años más tarde, también bloqueó nuevamente la posibilidad de establecer mecanismos de intercambio político entre el gobierno y las oposiciones partidarias. El inédito diálogo que Perón y el radical Balbín, los jefes de los dos grandes partidos, abrieron en 1970 , contribuyó a frustrar el intento de continuismo militar que impulsó el presidente Lanusse entre 1971 y 1973. Pero el diálogo se quebró en 1974 cuando murió Perón y sus sucesores se inclinaron por el rechazo de los procedimientos institucionales al proponerse la liquidación de las oposiciones internas a cualquier costo.

Las casi tres décadas de inestabilidad institucional tuvieron un efecto obvio: las políticas gubernamentales explícitas se caracterizaron por su alto grado de discontinuidad. Sin embargo, hasta 1975 esta discontinuidad no afectó gravemente a la economía argentina; como lo señaló Díaz Alejandro, las tasas de crecimiento del producto, aunque modestas, fueron siempre positivas. La discontinuidad de las políticas públicas fue en realidad uno de los componentes de una matriz política y económica en la cual, a partir de 1955, se exacerbó el sesgo antiinstitucional de los comportamientos de los principales actores. Veamos qué quiero decir con esto.

A partir de ese último año se fue reproduciendo un patrón de aprendizaje colectivo de carácter negativo; su rasgo más significativo fue que los distintos actores utilizaron el chantaje 
en contra de las instituciones como un arma privilegiada en las pujas distributivas y políticas. Por cierto que los peronistas fueron uno de los principales transgresores de las reglas institucionales, pero esto resultó natural dado que esas reglas los excluían del juego político. Sin embargo, la falta de compromiso con las instituciones políticas se extendió al conjunto de los actores; la estabilidad institucional, o más precisamente las amenazas de desestabilización, se convirtieron en una ficha más que se jugó en el tablero de la política argentina.

Los gobiernos, incluso aquellos que se inauguraban con imágenes de fortaleza, terminaban huérfanos de apoyos de los actores relevantes y aislados de la mayoría de la población. En una suerte de estatismo antigubernamental todos demandaron recursos del Estado, al mismo tiempo que muchos de los actores conspiraron, directa o indirectamente, en contra del gobierno de turno.

Se ha afirmado a menudo que, a partir de la coyuntura de la primera guerra mundial, Argentina fracasó en llenar las expectativas que había generado previamente. Los procesos desplegados a partir de 1880: rápida expansión económica, desarrollo de la infraestructura física y la educación pública, construcción de un Estado nacional verosímil y organización de una arquitectura constitucional relativamente estable habían alimentado la idea de que Argentina, a semejanza de Canadá y Australia, se integraría al pequeño grupo de nuevas naciones que se incorporarian al universo de los países desarrollados.

LOS PARTIDOS POLITICOS ARGENTINOS
Para recordar la terminología rostowiana, Argentina efectivamente no llegó a "despegar". Sin embargo, el país transitó las seis décadas que siguieron al comienzo de la primera guerra mundial sin sufrir grandes traumas políticos o económicos. La economía continuó creciendo, aunque a un ritmo mucho más modesto que la de aquellos países con los cuales Argentina había sido comparada a principios del siglo XX. Asimismo, la sociedad no perdió su carácter integrativo al no interrumpirse la incorporación en sus distintos espacios de la gran mayoría de la población. Es cierto que las conductas habituales descansaron en el permanente quebrantamiento de las reglas. Sin embargo, los actores se abstuvieron de tener comportamientos límite, es decir aquellos que apuntaran al aniquilamiento de los adversarios sociales y políticos, o se tradujeran en el abandono de los patrones implícitos en los que se apoyaba el orden social.

Durante muchas décadas, entonces, Argentina no explotó, ni se derrumbó el orden social y económico. Sin embargo, la repetición de los ciclos de inestabilidad política tuvo como efecto que se fueran acumulando dilemas y conflictos no resueltos. La clausura de la primera experiencia democrática en 1930, y el fracaso de los intentos de reconciliación entre radicales y conservadores a fines de esa misma década, sellaron el cisma entre el sistema partidario en su conjunto y los sectores capitalistas; tanto agropecuarios, como financieros, comerciales e industriales. Este cisma se instala- 


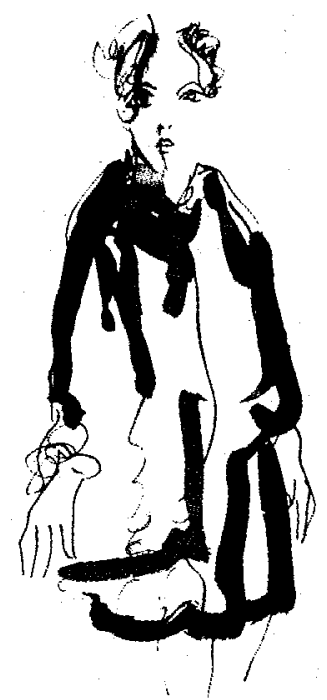

ría, de modo subyacente o abierto, como un problema no resuelto de la política argentina.

El peronismo de la década de 1940 constituyó, en principio, una reacción al bloqueo de la representación popular, pero el despliegue de la fórmula peronista tampoco contribuyó a la posibilidad del desarrollo de las prácticas de la democracia representativa. Por eso, cuando cayó en 1955, la desarticulación del personalismo plebiscitario de Perón no hizo más que traer nuevamente a la superficie las dificultades para establecer una democracia política.

El cuarto de siglo abierto en 1955 estuvo dominado por la militarización de la política; este proceso culminó a mediados de la década de 1970 cuando, sobre todo desde las fuerzas armadas, pero también desde la guerrilla, se plantearon proyectos que despreciaron la política institucional y se propusieron el exterminio de los adversatios. El desenlace es conocido: la guerrilla fue efectivamente liquidada en un par de años, pero sus verdugos también se autoaniquilaron políticamente un lustro más tarde. En 1983, entonces, se inauguró una nueva experiencia democrática que, a pesar de la turbulencia militar de fines de esa década, vio desaparecer la espada de Damocles que había pendido sobre sus predecesores. Sin embargo, el caos económico de 1988 y 1989, y la experiencia de la hiperinflación, sugirieron que los gobier- 
nos, pero más genéricamente la politica argentina, se enfrentaban a nuevos problemas, que iban más allá de la estabilización de los mecanismos institucionales. Discuto este tema, aunque sin desarrollarlo siquiera mínimamente, en la última sección del artículo.

\section{LOS NUEVOS SENTIDOS DE POLITTICA} (1983-1994)

Como se señala en el planteo inicial, el año de 1983 constituyó un punto de inflexión crítico de la política argentina. La singularidad de esa coyuntura está vinculada a que en ella se produjo un doble desplazamiento de la política de efectos parcialmente contradictorios; esta última circunstancia resulta especialmente evidente si se repara en los partidos políticos.

Por un lado, la transición hacia una democracia representativa naturalmente convirtió a los partidos políticos en los principales actores del sistema. El derrumbe de la dictadura militar hizo perder verosimilitud a modalidades alternativas de organización del régimen político. Durante la década siguiente se consolidaron las instituciones representativas y en particular los partidos políticos, al ir desapareciendo gradualmente los cuestionamientos que los militares, directamente, y los grandes empresarios, más indirectamente, habian hecho tradicionalmente a las reglas y prácticas democráticas.

Pero, por otro lado, la desestatización de la economía y de la política a la que me referí en el punto anterior disolvió en gran medida el sustrato mismo de los estilos de acción partidaria que se habían conformado en el marco de la matriz Estado-céntrica.

Los partidos en Argentina, a pesar de sus reiterados fracasos en constituirse como sistema, no habían sido fenómenos irrelevantes. Sin embargo, la esencia de la acción partidaria había estado vinculada a la capacidad de las distintas fuerzas para contribuir a la articulación de conductas sociales orientadas a extraer recursos del Estado recurriendo a menudo a mecanismos diversos de chantaje. En el límite se trataba de saquear al Estado, a partir de reducir a los sucesivos gobiernos a la impotencia en el terreno de la fijación y la puesta en marcha de políticas. Eso lo sabían hacer los partidos, aunque por supuesto la habilidad era también compartida por otros actores de la política argentina, como los empresarios y los militares.

Para los partidos, empero, el juego tenía necesariamente resultados que, en última instancia, eran insatisfactorios. Cada éxito en los intentos de encarnar demandas y reivindicaciones sociales tenía mucho de victoria pírrica, pues contribuía a desarticular intermitentemente uno de los pilares necesarios para la institucionalización de las prácticas partidarias: las organizaciones y las políticas gubernamentales que se apoyaban en los mecanismos de la democracia representativa.

Pero en la coyuntura actual, la posibilidad de alcanzar resultados parcialmente exitosos a través de la erosión de la gobernabilidad se ha agotado. Salvo algunos reducidos enclaves clientelistas tradicionales, la alternativa de extraer rentas del Estado 
está prácticamente anulada. Por ende, los reflejos que los partidos desarrollaron durante varias décadas se han tornado contraproductivos. La hiperinflación de 1989 corroboró lo que ya habían sugerido los cuadros políticoeconómicos que se perfilaron, con menor crudeza, en 1975 y 1982-83: el desgobierno de la economía enfrentaba a la sociedad con el riesgo último de un colapso de las normas que permitian el mantenimiento del orden social. Frente a la virtual desaparición de la moneda, partidos especializados en la oposición quedaron inermes. Obviamente esta circunstancia afectó especialmente al partido que estaba en el gobierno, la Unión Cívica Radical, que no sólo fue derrotado en las elecciones presidenciales de 1989 , sino que se vio forzado a ceder el gobierno de manera anticipada.

En ese punto se produjo un viraje de la política argentina que puede llegar a ser decisivo. Trece años después de ser expulsado por los militares, retornó al poder el peronismo. Su candidato, Carlos Menem, pareció encarnar un hiperpopulismo pasado de moda y nacionalista: aparte de prometer un "salariazo", también propuso la moratoria de la deuda y la recuperación de las islas Malvinas. " Además el propio partido se perfilaba como el menos apropiado para gobernar en la situación de aguda crisis económica: su experiencia histórica se había reducido al gobierno en un periodo inicialmente definido por la facilidad para redistribuir recursos, como la segunda mitad de la década de los cuarenta,

11 Canitrot y Sigal, "Economic", 1994. y sobre todo al ejercicio del papel de oposición proscrita y/o hostil al gobierno de turno. ${ }^{12}$

Sin embargo, Menem, advertido de que su sobrevivencia política estaba condicionada por la superación del síndrome de hiperinflación y caos social, produjo dos innovaciones radicales. Por un lado, en el plano partidario, el nuevo presidente impulsó un acuerdo con la Unión del Centro Democrático (UCD), partido de derecha creado por el perenne ideólogo del liberalismo económico, Álvaro Alsogaray. Esta agrupación había alcanzado prácticamente el diez por ciento de los votos en las elecciones para diputados de aquel mismo año y la alianza con la UCI) no sólo rompía con la tradicional divergencia peronismoantiperonismo que había dominado la política argentina desde 1945, sino que también señalaba la predisposición del nuevo peronismo a quebrar su renuencia tradicional a reconocer plenamente la legitimidad de la arena partidaria.

Por otro lado, Menem percibió que el problema principal que afrontaba el Estado, y la sociedad argentina, era la retirada -o la "salida" en términos hirschmanianos- de los empresarios del espacio de las estrategias cooperativas, y su capacidad para producir situaciones de facto que jaqueaban

12 In cstc sentido, cl interregno de 19731976 no constituyó una cxcepción a la dialéctica en la que se movió el peronismo entre 1916 y 1989, puesto que en aquellos años la mayoría de los sectores del partido se caracterizaron por el sabotajc reiterado de las políticas gubernamentales, a pesar de que nominalmente el peronismo estaba en el poder. 
permanentemente a las debilitadas instituciones políticas. Por tanto, el presidente estimó que sólo una alianza con los representantes más conspicuos de la gran burguesía podía dar al gobierno la posibilidad de reestabilizar la economía. Para ello designó a un par de gerentes de uno de los clanes empresariales más poderosos del país, el conglomerado Bunge $\&$ Born, para que se hicieran cargo del manejo de la política económica. De ese modo se

estableció por primera vez en la historia del país una coalición entre el posecdor de la mayoría de los votos y el centro económico decisorio con capacidad para inlluir decisivamente sobre el logro del equilibrio macroeconómico. ${ }^{13}$

La alianza con Bunge \& Born se desbarató a los pocos meses, y ello generó un nuevo brote hiperinflacionario a fines de 1989; el gobierno peronista también fracasó con su programa estabilizador de 1990 , a pesar de la fuerte reducción del déficit fiscal y de la privatización de empresas y servicios públicos. Sin embargo, y no obstante los fracasos, los intentos iniciales crearon el sustento para el lanzamiento del plan de convertibilidad orquestado por el cuarto ministro de Economía peronista, Domingo Cavallo. Éste tendría más éxito en la recuperación de la estabilidad monetaria y también en el logro de tasas satisfactorias de crecimiento económico entre 1992 y 1994. 216.

13 Cavaro\%i y Landi, "Political", 1992, p.
El éxito, aunque todavía parcial y precario, de las políticas económicas a partir de 1991, descansó en el nuevo tono discursivo del peronismo anunciado a partir de la asunción del gobierno de Menem: la postulación de un proceso radical de privatización y desregulación que dio un giro antiestatista y aperturista a orientaciones que durante 45 años habían estado asociadas en buena medida a lo contrario. Después de los traspiés del periodo inicial, el atractivo del gobierno menemista quedó reafirmado por la cadena de triunfos electorales que alcanzó el partido oficialista. Tanto en 1991 y 1993, cuando se celebraron elecciones de renovación parlamentaria, como en 1994, cuando fueron electos representantes a la asamblea general constituyente de ese año, el peronismo alcanzó la primera mayoría a la par que la oposición se fragmentaba en la medida que los partidos más importantes, la Unión Cívica Radical, la UCD y el Partido Intransigente, de centro izquierda, iban perdiendo votos y representación parlamentaria. ${ }^{14}$

in Descle la década de 1950, los gobicrnos civiles se habían enfrentado con una valla que no habían podido superar y que, en todos los casos, había contribuido decisivamente a su derrocamicnto o, en cl caso de Alfonsín en 1987, a su pérdida total de cfectividad como cjecutor de políticas verosímiles: las clccciones del cuarto año. Cada uno de csos gobiernos había sultido una derrota en esa conticnda, cn la cual se renovaban diputados y gobernadores provincialcs; la consecucncia había sido la debacle. Mencm no sólo cvitó cl síndrome del cuarto año, sino que además logró la mayoría que le pernitiós reformar la Constitución nacional cn 1994 . 
Empero el continuado appeal del peronismo no se debió solamente a la efectividad de su giro antiestatista, sino también a la habilidad que demostró Menem para capitalizar, y a la vez promover, otro fenómeno que, a partir de 1987, se extendió en la sociedad argentina paralelamente al derrumbe material y normativo del intervencionismo estatal: el predominio de orientaciones antipolíticas en segmentos significativos de la población.

Algunas de las instituciones debilitadas por esas orientaciones han sido precisamente los partidos políticos, y a este proceso no ha sido ajeno el estilo de acción presidencial. Los partidos, incluido el propio peronismo, han sido marginados de manera casi absoluta no sólo de la gestión de las políticas, sino también del debate, tanto parlamentario como extraparlamentario, de las mismas. Han contribuido a ello, amén de las actitudes de la población y el mismo tono menemista, la incapacidad de los propios partidos para generar opciones de gobierno sin subordinarse exclusivamente a los parámetros del ajuste y la estabilización, o refugiarse en el oposicionismo populista. Así se ha ido conformando un estilo de gobierno que si bien recurre a los partidos en las instancias electorales, los margina totalmente en la política cotidiana. El sistema emergente, al cual se podría caracterizar como feo, aunque democrático, introduce un alto grado de incertidumbre. Esta última tiene que ver, sobre todo, con la circunstancia, que no debe descartarse totalmente, de que el itinerario del ajuste económico y el retorno estable de tasas de crecimiento sostenido requieran la (re)construcción de mecanismos de negociación política. En ese punto, la necesidad de que los partidos funcionen como actores centrales de un sistema de intercambios podría tornarse más evidente, pero el descentramiento que han sufrido durante la última década también podría haber generado un proceso de difícil reversibilidad.

\section{BIBLIOGRAFÍ}

-Berins Collier, Ruth y David Collier, Shaping the political arena, Princeton University Press, Princeton, 1991.

-Canitrot, Adolfo y Silvia Sigal, "Economic reform, democracy and the crisis of State in Argentina", en Joan Nclson (comp.), a precarious balance. Democracy and econonic reforms in Lalin America, International Center for Economic Growth, San Irancisco, 1991.

-Cavarozzi, Marcclo, Aulorilarismo y democracia, Centro Editor de América Latina, Buenos Aires, 1983.

_- "Politics: a key for the long term in South America", en William Smith, Carlos Acuña y Fduardo Gamarra (comps.), Latin american political economy in the age of neoliberal reform, Transaction, Ncw Brunswick, 1994.

-, y Oscar Iandi, "Political parties under Alfonsin and Menem", en Edward Iipstcin (comp.), The neu argenline democracy, Praeger, Connecticut, 1992.

-De Riz, Liliana, Retorno y derrumbe: el último gobiemo peronisia, Folios, Mćxico, 1981.

-O'Donncll, Guillermo, Modernization and bureaucralic-authoritarianism, Institute of International. Studies, University of California, Berkelcy, 1973. 